\title{
DEFINIÇÃO DO ANO CLIMÁTICO DE REFERÊNCIA (TRY) PARA A CIDADE DE PALMAS- TOCANTINS
}

Paper title Definition of Test Reference Year (TRY) for the city Palmas-Tocantins

Definición del año climático de referencia (TRY) para la ciudad de Palmas-Tocantins

Ana Maria Meneses Ferraz ${ }^{* 1}$, Mariela Cristina Ayres de Oliveirra ${ }^{2}$

${ }^{1}$ Graduanda em Engenharia Elétrica, Curso de Graduação, Universidade Federal do Tocantins, Palmas, Brasil.

${ }^{1}$ Dra, orientadora do curso de Arquitetura e Urbanismo, Universidade Federal do Tocantins, Palmas, Brasil.

*Correspondência: NEUCIDADES, bloco 1, sala 18, Av. NS 15, 109 Norte, Palmas, Tocantins, Brasil. CEP:77.010-090.e-mailannamaria_1992@hotmail.com

Artigo recebido em 25/08/2019 aprovado em 12/03/2020 publicado em 31/03/2020.

\section{RESUMO}

O desenvolvimento dessa pesquisa se baseia na coleta de dados climáticos da estação meteorológica automática local do INMET e sua sistematização, em busca da definição do Ano Climático de Referência- TRY como fundamento para elaborar uma Carta Bioclimática para a cidade de Palmas- TO. Para isto, fundamentou- se em trabalhos anteriores para diferentes localidades como a Carta Bioclimática de Cuiabá por Leão (2007), sobretudo aplicando a mesma metodologia para a determinação do TRY, de ASHARAE (1993). Tal metodologia se baseia na reunião das médias mensais de Temperatura de Bulbo Seco (TBS) de pelo menos 10 anos consecutivos, em seguida, a eliminação de anos com extremos de temperatura até que se tenha apenas um, sendo considerado o TRY para aquela localidade. Os anos tratados se delimitaram entre os anos de 2008 a 2017. Chegou- se ao TRY local como sendo o ano de 2015. Com a inserção das 8760 horas do TRY no AnalysisBIO, foi possível a geração da Carta Bioclimática. As horas de desconforto por calor para Palmas chegam a $74,3 \%$ do total de horas no ano. As principais estratégias bioclimáticas sugeridas pela simulação para o calor foram: a ventilação, alta inércia para o resfriamento, resfriamento evaporativo e ar condicionado.

Palavras-chave: TRY, arquitetura bioclimática.

\section{ABSTRACT}

The development of this research is based on the collection of climate data from INMET's site automatic weather station and its systematization, in search of the definition of the TRY Climate Reference Year as the basis for preparing a Bioclimatic Chart for the city of Palmas-TO. For this, it was based on previous work for different locations such as the Cuiaba Bioclimatic Charter by Leo (2007), mainly applying the same methodology for the determination of TRY by ASHARAE (1993). This methodology is based on the monthly Dry Bulb Temperature averages of at least 10 consecutive years, then the elimination of years with temperature extremes until there is only one, being considered the TRY for that location. The treated years were delimited from 2008 to 2017. The local TRY was reached as of 2015. With the inclusion of the 8670 hours of TRY in Analysis Bio, it was possible to generate the Bioclimatic Chart. The hours of heat discomfort for Palms reach $74.1 \%$ of the total hours in the year. The main bioclimatic strategies suggested by the heat simulation were ventilation, high cooling inertia, evaporative cooling and air conditioning.

Keywords: TRY, bioclimatic architecture.

\section{RESUMEN}

El desarrollo de esta investigación se basa en la recopilación de datos climáticos de la estación meteorológica automática local de INMET y su sistematización, en busca de la definición del Año de Referencia Climática TRY como base para preparar un arquivo bioclimático para la ciudad de Palmas-TO. Con este fin, se basó en trabajos previos para diferentes ubicaciones, como la Carta Bioclimática de Cuiabá de Leão (2002), aplicando principalmente la misma metodología para la determinación de TRY por ASHARAE (1993). Esta metodología se 
basa en los promedios mensuales de temperatura de bulbo seco de al menos 10 años consecutivos, luego la eliminación de años con temperaturas extremas hasta que solo haya uno, siendo considerado el TRY para esa ubicación. Los años tratados se delimitaron de 2008 a 2017. El TRY local se alcanzó en 2015. Con la inclusión de las 8670 horas de TRY en AnalysisBio, fue posible generar el Gráfico Bioclimático. Las horas de incomodidad por calor para Palmas alcanzan el $74.1 \%$ del total de horas en el año. Las principales estrategias bioclimáticas sugeridas por la simulación de calor fueron ventilación, alta inercia de enfriamiento, enfriamiento evaporativo y aire acondicionado.

Descriptores: TRY, arquitectura bioclimática.

\section{INTRODUÇÃO}

O urbanismo e a arquitetura bioclimática proporcionam ao homem as melhores condições físicas e mentais de habitabilidade nas cidades e, consequentemente, nos edifícios, com um mínimo de dispêndio energético associado a um mínimo impacto do meio ambiente (BARBOSA, 2010). Quando se trata de arquitetura bioclimática, Barbosa (2010) a conceitua como sendo "o estudo que busca a harmonização das construções ao clima e características locais".

De acordo com Lanham, Gama e Braz (2004,), tal arquitetura implica dois fatores em seu contexto: a multidisciplinaridade, para concepção de um projeto eficiente; e a sua inserção no tema sustentabilidade.

Lima (2005) entende que para adequar o urbanismo e a arquitetura ao clima de um determinado local significa construir espaços que possibilitem ao homem condições de conforto. Os benefícios disso é a obtenção de conforto ambiental e a redução máxima de custos de manutenção em iluminação, ventilação e climatização na fase de uso de uma edificação assim pensada.

Nos Estados Unidos, já na década de 60, os irmãos Olgyay aplicaram a bioclimatologia na arquitetura, considerando o conforto térmico humano, e criaram a expressão "projeto bioclimático". Delimitando a relação entre clima e projeto arquitetônico, configurou-se um manual para projeto bioclimático, com particular referência à carta bioclimática, sendo esta a primeira representação gráfica a mostrar a conexão entre clima e o conforto humano (LEÃO, 2007). Tal ferramenta sugere medidas corretivas do clima para as condições internas da edificação. Essas medidas buscam atingir conforto quando o ponto de estudo está fora da zona de conforto, quantificando a necessidade de estratégias passivas diante das condições climáticas oferecidas, ou ativas, quando necessárias. A proposta de Givoni (1969), desenvolvendo a ideia de Olgyay, apresenta uma carta bioclimática baseada na carta psicromética, que inclui temperatura de bulbo seco, umidade relativa, a pressão de vapor e a temperatura de bulbo úmido.

Em 1969, Givoni desenvolvendo a idéia de Olgyay, propõe uma carta bioclimática para edificações, baseada na carta psicrométrica, que inclui, além da temperatura de bulbo seco e da umidade relativa, a pressão de vapor e a temperatura de bulbo úmido. Com o perfil bioclimático do local, os profissionais da área de projeto podem obter indicações fundamentais sobre as estratégias a serem adotadas no projeto bioclimático. A carta bioclimática de Givoni (1969), é adaptada para países de clima quente e em desenvolvimento, portanto adotada para o Brasil, e segundo Lamberts et al., (1997) sintetizam num diagrama psicrométrico os tipos de estratégias que devem ser utilizados.

O ponto de partida para avaliação bioclimática no projeto é verificar a disponibilidade dos dados climáticos do local. Assim, é possível elaborar arquivos bioclimáticos e submetendo a diversas metodologia disponíveis, pode-se obter indicações 
fundamentais sobre as estratégias a partir da análise bioclimática do local por meio da carta bioclimática.

Menos de 4\% dos mais de 5.500 municípios brasileiros possuem dados climáticos publicados. Além disso, uma das principais dificuldades enfrentadas pelo Brasil na simulação termo energética de edifícios é a falta de dados climáticos de qualidade (CAMPOS; SAKIYAMA; OLIVEIRA, 2016).

Nesse sentido, este trabalho baseia-se nas diretrizes ambientais e variáveis climáticas que interferem no Clima local da cidade de Palmas- TO, bem como contribuir para a concepção de uma ferramenta por meio do tratamento adequado de dados climáticos locais e a inserção deles sob forma de arquivo bioclimático em softwares para este fim, que permita traçar um perfil climático local e ser um recurso para o dimensionamento de edificações locais no que diz respeito ao conforto térmico e eficiência energética em edificações.

O objetivo do mesmo é definir o Ano Climático de Referência (Test Reference Year - TRY) para a cidade de Palmas- TO, por meio da metodologia desenvolvida pela ASHRAE (1993) e descrita por Goulart (1998), de modo que este conjunto de dados se torne a base para a criação de um arquivo climático a ser utilizado em softwares de simulação energética que busque a análise e correção de variáveis divergentes quando comparado a outras bases de dados existentes e passíveis de discussão, como as tentativas anteriores de se criar uma carta bioclimática local e até referências que usualmente se utilizam como as diretrizes de conforto ambiental utilizadas a partir da carta bioclimática de Porto Nacional, localizada a 60 km da Capital.

Embora ainda não haja estudos no Brasil comparando os diversos métodos de seleção do ano climático representativo que vem sendo utilizados pelo mundo, para encontrar aquele que seja o mais adequado, os dois principais métodos utilizados no país são o TRY e o TMY_br. (GUIMARAES, 2016).

A metodologia de definição do TRY, ferramenta deste presente estudo, também foi utilizada por dezenas de autores em suas pesquisas como Leão (2007), Flores (2014), Rossi e Krüger (2015) e Guimaraes (2016), entre outros.

Palmas é um município brasileiro localizado na região central do estado de Tocantins. As coordenadas da sede municipal são: latitude $10^{\circ} 11^{\text {' }}$ 04" Sul e longitude $48^{\circ} 20^{\prime}$ 01" Oeste. A altitude média do município de Palmas é de 330 metros acima do nível do mar. A cidade está inserida numa região com altas temperaturas, praticamente o ano todo, sendo que as normais climatológicas demonstram que predomina o clima tropical com estação seca e temperatura média anual de $26^{\circ} \mathrm{C}$, segundo a classificação climática de Köppen-Geiger. A média das máximas é $36^{\circ} \mathrm{C}$ e ocorre em setembro, enquanto a mínima é $22^{\circ} \mathrm{C}$ e ocorre em julho. De acordo com a Norma 15220 - 3: Desempenho térmico de edificações - Parte 3: Zoneamento bioclimático brasileiro e diretrizes construtivas para habitações unifamiliares de interesse social, a cidade de Palmas apresenta características climatológicas referentes a Zona 8. Como diretrizes construtivas para adaptar o edifício ao clima local, as recomendações construtivas para essa Zona são para aberturas grandes e totalmente sombreadas, o uso de paredes e coberturas leves e refletoras.

A estratégia bioclimática recomendada é o uso de ventilação cruzada o ano todo. A norma adverte que apenas o condicionamento passivo não será suficiente durante as horas mais quentes. Diante dos resultados obtidos com o estudo das condições climáticas de um determinado local, estas podem ser utilizadas para favorecer as condições de conforto em ambientes internos através de recursos arquitetônicos (DIAS, 2009). De modo geral, a edificação funciona como um 
anteparo entre o usuário e o meio, dotado de mecanismos estratégicos projetados por profissionais, baseado nas variáveis oferecidas pelo clima. Esses mecanismos são criados para suprir as exigências das diretrizes bioclimáticas, sugeridas genericamente de acordo com os elementos e fatores climáticos apresentados (LEÃO, 2007).

\section{MATERIAIS E MÉTODOS}

Inicialmente, houve a tentativa de construção do Arquivo Climático em extensão *.EPW de forma equivocada por meio da obtenção dos dados climáticos iniciais tomados a partir do banco que a estação convencional que INMET disponibiliza, isso porque a metodologia não se ajustou aos dados climáticos locais disponíveis. A partir daí, para a construção do TRY, seriam necessários dados correspondentes a cada hora. Então, a pesquisa se ateve à busca desses dados climáticos horários. Para tanto, foi solicitado novamente junto ao INMET, mas agora, tendo como base a estação automática.

O TRY é identificado a partir de um procedimento que utiliza somente as temperaturas médias mensais de bulbo seco dos anos estudados.

Pela dificuldade de aquisição de dados climáticos para a região local do município, a sequência da pesquisa ficou comprometida no que tange ao tempo de desenvolvimento da mesma, pois demanda além da base de dados, o tratamento minucioso dos mesmos.Com base na metodologia elaborada pela ASHRAE (1993) e descrita por Goulart (1998), as médias mensais das temperaturas de bulbo seco do período de 2008 a 2017 foram dispostas sequencialmente (Quadros 1 e 2).

Em seguida, utilizando os critérios de eliminação de anos com extremos de temperaturas mensais foi definido o Ano Climático de ReferênciaTRY local (Quadro 3).
Para a confecção da Carta Bioclimática e das estratégias indicadas para o clima de Palmas- TO, a análise estatística do Ano Climático de Referência torna-se essencial para verificar a coerência da caracterização climática da cidade através do ano típico. Por meio das variáveis climáticas contidas no ano representativo, é possível sua adequação à programa de simulação e eficiência energética que servem para descrição representativa anual do clima local, e indicam estratégias bioclimáticas apropriadas para intervenções na fase ainda de projeto para edificações e edifícios.

A metodologia se restringe à quatro etapas: 1) estudos do clima local e suas variáveis levando em consideração também de tentativas anteriores de se elaborar uma carta bioclimática local; 2) a busca de dados climáticos locais em estações meteorológicas com as variáveis que caracterizam o clima; 3) concepção do arquivo climático de referência por meio do tratamento adequado dos dados climáticos, a determinação do Ano Climático de Referência (TRY); e 4) a adequação aos formatos aceitos pelos programas computacionais de simulação energética, nesse caso, a inserção de normais do TRY no programa AnalysisBIO. As etapas mencionadas anteriormente são descritas com mais detalhes a seguir:

$1^{a}$ Etapa: Esta etapa é restrita ao entendimento do clima local por meio do estudo das bibliografias disponíveis e de tentativas anteriores de se construir uma carta bioclimática local de trabalhos anteriormente realizados.

$2^{a}$ Etapa: Durante esta etapa foi compilado dados climáticos horários de 10 anos consecutivos, de 2008 a 2017 da Estação Automática Palmas-A009, código OMM 86607 localizada na Latitude: $10,190744^{\circ}$ e Longitude: $-48,31811^{\circ}$, junto ao INMET.

$3^{a}$ Etapa: Nesta etapa, os dados climáticos obtidos no banco de dados do INMET foram tratados 
conforme a metodologia utilizada para a determinação do arquivo TRY. Com os 10 anos de dados climáticos locais recolhidos, foram necessários ajustes no que se refere ao preenchimento de falhas horárias por meio processo de interpolação dos dados válidos $\mathrm{e}$ analisados a partir da tendência dos existentes. Em seguida, definiram-se as médias mensais de temperaturas de ano a ano, ambos com auxílio de rotinas desenvolvidas em planilhas eletrônicas no Excel. Depois, determinou o TRY seguindo a metodologia utilizada por Goulart et al. (1998) que se baseia na eliminação de anos de dados, os meses segundo sua importância para cálculo de energia e eliminação dos extremos.

De acordo com Leão (2007) a sequência utilizada no processo de determinação do TRY é dada por:

a) Dispor em sequência cronológica as médias mensais de TBS para o período de anos consecutivos disponíveis e obter as médias das médias mensais (Quadros 1 e 2);

b) Identificar e classificar os meses mais quentes e mais frios, dispondo em sequência o $1^{\circ}$ mês mais quente, em seguida o $1^{\circ}$ mês mais frio equivalente ao $1^{\circ}$ mês mais quente, o $2^{\circ}$ mês mais quente, o $2^{\circ}$ mês mais frio equivalente ao $2^{\circ}$ mês mais quente, e prosseguir até o décimo segundo mês mais frio em contrapartida ao seu equivalente $12^{\circ}$ mês mais quente (Quadros 1 e 2);

c) Para esta sequência dos últimos 10 anos, todos os anos sequenciais foram eliminados antes do final da análise do último ano. Portanto, o último ano foi considerado como um ano representativo do clima local, com características mais amenas diante dos outros anos analisados.

4ªtapa: A partir da escolha do TRY, um arquivo no formato *.try foi elaborado. Detalhadamente, é importante não confundir um arquivo com extensão try (*.try) com um arquivo TRY
(Test Reference Year). Segundo Carlo e Lamberts (2005), o TRY é então uma série de dados climáticos tratados segundo uma metodologia e representa uma situação referencial do clima do local em questão, enquanto o arquivo com extensão *.try é um formato para uso específico em um programa computacional de difícil visualização. Para a construção deste arquivo, foi necessária a confecção de um arquivo como "dados de entrada" e alguns procedimentos:

a) Os dados de TBS e URM (Umidade relativa média) foram digitados em duas colunas distintas para cada variável, sem vírgula ou ponto $\left(22,3^{\circ} \mathrm{C}=223\right)$, e cada hora era uma linha da planilha do programa Excel/Office. No total, o arquivo contava com 8760 linhas e duas colunas.

b) A utilização da planilha Excel serviu para tratamento e análise dos dados inválidos ou inexistentes. Foram aplicadas fórmulas para atingir a tendência dos dados e testes lógicos para identificação de falhas de digitação. Neste caso, foram limitados valores entre as temperaturas absolutas máximas e mínimas para identificação de erros na digitação.

c) Em seguida, os dados foram transportados para o programa Bloco de Notas/Office, para formação de um arquivo de extensão texto (*.txt) separado por tabulações. Em geral, o procedimento utilizou as funções "recortar" e "colar" diretamente do arquivo (TRY_Palmas. xls) para (TRY_Palmas. txt).

d) Com o arquivo CBA. txt foi gerado o arquivo CBA.TRY já no programa AnalysisBIO. Utilizou-se o caminho (FERRAMENTAS / GERAR TRY). O arquivo CBA. TRY foi salvo na pasta dos arquivos de programa do software.

e) Posteriormente, utilizou-se o caminho (ANÁLISE BIOCLIMÁTICA / CBA. TRY). 
Com a carta aberta foi informada em (OPÇÕES / PRESSÃO), a altitude de 182 metros do aeroporto de Cuiabá, local de coleta dos dados.

f) Em seguida, em (OPÇÕES / ANO TODO) a carta bioclimática foi plotada. Junto à carta, o programa oferece também um relatório com o cálculo da percentagem de horas do ano dentro e fora da zona de conforto e percentagem necessária de cada estratégia bioclimática, em (OPÇÕES / RELATÓRIO).

Quadro 1 - Médias mensais de Temperatura Bulbo Seco (TBS) em ${ }^{\circ} \mathrm{C}$ com extremos de temperatura mensais destacados (Janeiro a Junho).

\begin{tabular}{|c|c|c|l|l|l|l|}
\hline Ano & Jan & Fev & Mar & Abr & Mai & Jun \\
\hline 2008 & 25,7 & 25,21 & $\mathbf{2 4 , 2 6}$ & 25,13 & $\mathbf{2 8 , 9 1}$ & $\mathbf{2 6 , 3 7}$ \\
\cline { 2 - 7 } 2009 & 26,39 & 25,43 & 26,04 & $\mathbf{2 4 , 9 7}$ & $\mathbf{2 5 , 7 7}$ & 26,8 \\
\cline { 2 - 7 } 2010 & 26,11 & 27,16 & $\mathbf{2 7 , 5 2}$ & 27,82 & 26,16 & 27,65 \\
\cline { 2 - 7 } 2011 & 25,19 & 24,86 & 25,27 & 26,28 & 26,94 & 26,84 \\
\cline { 2 - 7 } 2012 & 25,13 & 25,36 & 25,67 & 26,68 & 26,73 & 26,91 \\
\cline { 2 - 7 } 2013 & 26,6 & 26,6 & 26,58 & 26,97 & 27,78 & 27,14 \\
\cline { 2 - 7 } 2014 & 24,99 & $\mathbf{2 4 , 4 5}$ & 25,61 & 26,33 & 27,28 & 27,07 \\
\cline { 2 - 7 } 2015 & 25,27 & 25,74 & 24,28 & 25,26 & 26,24 & 27,59 \\
\cline { 2 - 7 } 2016 & $\mathbf{2 4 , 1}$ & $\mathbf{2 9 , 4 2}$ & 26,47 & $\mathbf{2 8 , 1 2}$ & 27,62 & $\mathbf{2 7 , 9 4}$ \\
\cline { 2 - 7 } 2017 & 25,73 & 25,45 & 26,14 & 26,74 & 26,87 & 27,32 \\
\hline \multicolumn{7}{|c|}{ Fonte: INMET, 2019.} \\
\end{tabular}

Quadro 2 - Médias mensais de Temperatura Bulbo Seco (TBS) em ${ }^{\circ} \mathrm{C}$ com extremos de temperatura mensais destacados (Julho a Dezembro).

\begin{tabular}{|c|c|c|c|c|c|c|}
\hline Ano & Jul & Ago & Set & Out & Nov & Dez \\
\hline 2008 & 26,73 & 29,2 & 30,54 & 29,7 & 25,67 & 25,78 \\
\cline { 2 - 7 } 2009 & 27,11 & 28,99 & 28,9 & 26,58 & 26,72 & 26 \\
\cline { 2 - 7 } 2010 & $\mathbf{2 8 , 3 9}$ & 28,77 & $\mathbf{3 1 , 1 4}$ & 28,3 & 26,49 & 26,21 \\
\cline { 2 - 7 } 2011 & 27,29 & 29,55 & 31,03 & 28,02 & 26,29 & 26,07 \\
\cline { 2 - 7 } 2012 & 27,36 & 28,65 & 30,04 & 30,43 & 26,67 & $\mathbf{2 8 , 5 1}$ \\
\cline { 2 - 7 } 2013 & 28,1 & 29,23 & 30,51 & 28,43 & 25,49 & 25,37 \\
\cline { 2 - 7 } 2014 & 27,77 & $\mathbf{2 7 , 9 9}$ & 29,42 & 28,54 & 26,08 & 25,48 \\
\cline { 2 - 7 } 2015 & 27,01 & 28,5 & 30,47 & 28,85 & 26,2 & $\mathbf{2 3 , 5}$ \\
\cline { 2 - 7 } 2016 & 27,51 & 29,29 & 29,74 & 28,1 & $\mathbf{2 7 , 9 3}$ & 26,81 \\
\cline { 2 - 7 } 2017 & $\mathbf{2 6 , 0 4}$ & $\mathbf{2 9 , 6 1}$ & 30,73 & $\mathbf{3 1 , 0 3}$ & 27,14 & 25,85 \\
\hline
\end{tabular}

Fonte: INMET, 2019.

*TBS destacadas em células laranja: A maior média de temperaturas de bulbo seco para cada mês em 10 anos consecutivos;
*TBS destacadas em células verdes: A menor média de temperaturas de bulbo seco para cada mês em 10 anos consecutivos;

Quadro 3 - Classificação dos meses por ordem de importância.

\begin{tabular}{|c|c|c|c|c|c|}
\hline MÊS & ANO & $\operatorname{TBS}\left({ }^{\circ} \mathrm{C}\right)$ & MÊS & ANO & $\operatorname{TBS}\left({ }^{\circ} \mathrm{C}\right)$ \\
\hline $\begin{array}{c}\text { Setembro mais } \\
\text { quente }\end{array}$ & 2010 & 31,14 & $\begin{array}{l}\text { Setembro } \\
\text { mais frio }\end{array}$ & 2009 & 28,9 \\
\hline Março mais frio & 2008 & 24,26 & $\begin{array}{c}\text { Março mais } \\
\text { quente }\end{array}$ & 2010 & 27,52 \\
\hline $\begin{array}{c}\text { Outubro mais } \\
\text { quente }\end{array}$ & 2017 & 31,03 & \begin{tabular}{|c|}
$\begin{array}{c}\text { Outubro mais } \\
\text { frio }\end{array}$ \\
\end{tabular} & 2009 & 26,58 \\
\hline $\begin{array}{c}\text { Fevereiro mais } \\
\text { frio }\end{array}$ & 2014 & 24,45 & $\begin{array}{c}\text { Fevereiro mais } \\
\text { quente }\end{array}$ & 2016 & 29,4 \\
\hline $\begin{array}{c}\text { Agosto mais } \\
\text { quente }\end{array}$ & 2016 & 30,3 & \begin{tabular}{|c|}
$\begin{array}{c}\text { Agosto mais } \\
\text { frio }\end{array}$ \\
\end{tabular} & 2014 & 27,99 \\
\hline Abril mais frio & 2009 & 24,97 & $\begin{array}{c}\text { Abril mais } \\
\text { quente }\end{array}$ & 2016 & 28,12 \\
\hline $\begin{array}{c}\text { Maio mais } \\
\text { quente }\end{array}$ & 2008 & 28,91 & Maio mais frio & 2009 & 27,94 \\
\hline $\begin{array}{c}\text { Janeiro mais } \\
\text { frio }\end{array}$ & 2014 & 24,99 & $\begin{array}{c}\text { Janeiro mais } \\
\text { quente }\end{array}$ & 2013 & 26,6 \\
\hline \begin{tabular}{|c|c|}
$\begin{array}{c}\text { Dezembro mais } \\
\text { quente }\end{array}$ \\
\end{tabular} & 2012 & 28,51 & $\begin{array}{c}\text { Dezembro } \\
\text { mais frio }\end{array}$ & 2013 & 25,37 \\
\hline $\begin{array}{c}\text { Novembro } \\
\text { mais frio }\end{array}$ & 2013 & 25,49 & $\begin{array}{l}\text { Novembro } \\
\text { mais quente }\end{array}$ & 2016 & 27,93 \\
\hline $\begin{array}{c}\text { Julho mais } \\
\text { quente }\end{array}$ & 2016 & 28,41 & Julho mais frio & 2008 & 26,91 \\
\hline Junho mais frio & 2008 & 26,37 & $\begin{array}{c}\text { Junho mais } \\
\text { quente }\end{array}$ & 2016 & 27,94 \\
\hline
\end{tabular}

Fonte: Autores, 2019

\section{RESULTADOS E DISCUSSÃO}

A presente pesquisa se dedica a uma nova tentativa de criar um arquivo bioclimático com o mesmo banco de dados climáticos que Roriz (2012) utilizou, a estação automática do INMET, porém com metodologia diferente da descrita e aplicada no desenvolvimento desse estudo

De acordo com as normas da ASHRAE (1993), dados do Ano Climático podem ser definidos em dois formatos distintos, o Test Reference Year (TRY), preparado pelo National Climatic Center e o Typical Meteorological Year (TMY), pelo Sandia Laboratories na cidade de Albuquerque nos Estados Unidos. Este último foi a metodologia aplicada por Roriz (2012) para a definição do ano climático de 411 cidades brasileiras, dentre elas Palmas, Tocantins. Em sequência, esses arquivos foram adequados ao formato *.EPW aceito pelo programa de simulação energética Energy Plus. O arquivo em formato *.EPW para Palmas, se restringiu aos anos de 2009 e 2005, sendo 
possível observar inconsistências de dados climáticos quando comparados ao clima local.

Roriz (2012) aponta que para grande parte dos municípios presentes na base do INMET foi possível montar poucos anos inteiros usando a metodologia do TMY, devido à dificuldade em se obter dados climáticos consistentes e que abrange longos períodos, assim, os arquivos representam baixa representatividade estatísticas das ocorrências climáticas históricas e carece de revisões a medida em que se disponha de intervalos de tempo mais longos. Leão (2007) explica o TMY como "uma compilação de meses sem extremos de temperatura provenientes de diferentes anos, gerando um ano climático que nunca existiu, mas que apresenta temperaturas sem extremos para cada mês". Como já abordado, para essa pesquisa optou-se pela metodologia de definição do TRY utilizada por Goulart et al. (1998). A escolha do Ano Climático de Referência se baseia na eliminação de anos que possuem dados de temperaturas médias extremas (altas e baixas) até que fique apenas um ano de dados médios.

A base de dados da Estação Automática do INMET, possui a coleta horária dos parâmetros climáticos, já a Convencional disponibiliza somente dados de 3 e 3 horas em horário UTC, daí o principal motivo da escolha pela estação automática, por esta se adequar a metodologia aqui limitada. Utilizou-se então, dados climáticos de médias mensais de temperatura do ar para um período de 10 anos (20082017) representantes e consistentes, coletados por meio da base da estação automática código OMM 86607, localizada na região leste do município de Palmas nas coordenadas de Latitude $-10,190744^{\circ}$ e Longitude $-48,301811^{\circ}$, com altitude de $292 \mathrm{~m}$.

A estação automática A009 instalada em Palmas ao Leste da cidade na região do Plano Diretor Sul na Quadra 112 sul, SR 7, registra dados de hora em hora em UTC (Coordinated Universal Time). As variáveis registradas no arquivo da estação automática são: temperatura do ar, temperatura máxima e mínima diária, umidade, pressão, velocidade e direção do vento, precipitação, insolação total diária.

O ano definido como o Ano Climático de Referência (TRY) foi o ano de 2015, isso se justifica mediante a análise das médias máximas e mínimas de temperatura de bulbo seco (quadros 1 e 2) classificadas por extremos de temperaturas (quadro 3). A metodologia determina que o TRY será o ano com o menor índice de extremos de temperaturas mensais, assim, o ano de 2015 não aparece na ordem de importância para cálculo de energia e eliminação dos extremos dispostos na quadro 3.

As variáveis climáticas respectivas ao ano de 2015, considerado o TRY, servem para descrição representativa do clima de Palmas durante um ano, e como ferramenta de utilização em programas que auxiliem na utilização das estratégias bioclimáticas indicadas como apropriadas para intervenções na fase ainda de projeto para edificações e edifícios.

Com o arquivo climático TRY em formato *.txt., foi possível a inserção e análise de mês a mês do ano no programa em que é possível a criação de cartas bioclimáticas, o AnalysisBio desenvolvido pelo LabEEE-UFSC. A carta bioclimática de Baruch Givoni, adaptada para países de clima quente e em desenvolvimento, portanto adotada para o Brasil LAMBERTS (1997), sintetiza num diagrama psicrométrico os tipos de estratégias que devem ser utilizados. Essas são determinadas a partir da distribuição dos pontos de convergência da temperatura de bulbo seco (TBS) e umidade relativa sobre as zonas estabelecidas, como mostra a figura 1.

Na Figura 1 encontra-se a carta bioclimática gerada especificamente Palmas. Foram inseridos e plotados no programa AnalysisBIO os dados de temperatura e umidade relativa do ar das 8760 horas 
do TRY, obtendo as estratégias bioclimáticas mais adequadas para as edificações ao longo do ano.

Figura 1 - Carta bioclimática de Palmas a partir das do TRY.

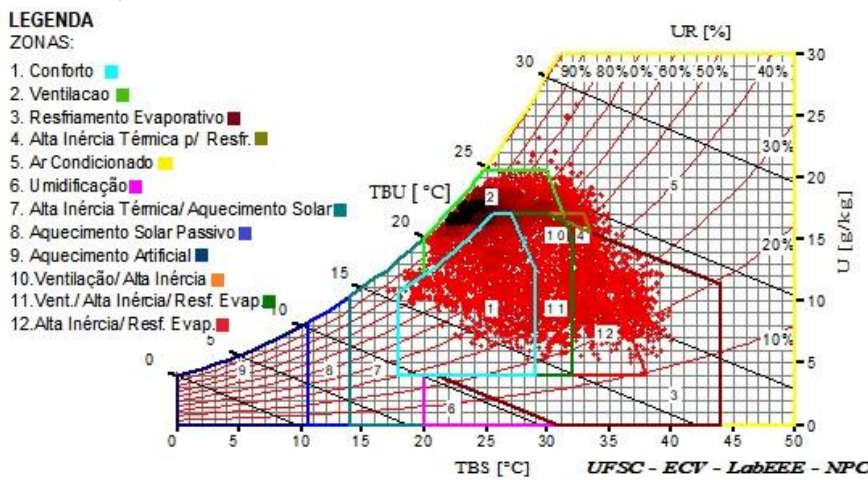

Fonte: Autores, 2019.

A carta bioclimática de Palmas indicou que para as 8760 horas anuais há um desconforto pelo calor de $74,3 \%$ do total, isso significa aproximadamente 6509 horas de desconforto anuais em média.

Houve a predominância de quatro estratégias para o desconforto pelo calor apontadas pela simulação. A estratégiapassiva de ventilação possui o maior percentual, atende $54 \%$ das horas de desconforto e pode ser útil para todos os meses do ano. Foi sugerida, ainda, a alta inércia térmica para resfriamento, uma alternativa passiva que pode abranger o percentual de $26,4 \%$ das horas de desconforto. A estratégia resfriamento evaporativo se restringiu como alternativa de intervenção para a 30\% das horas anuais de desconforto, concentrou a maioria dos dados horários anuais, menos para os meses de janeiro, março e dezembro, quando as temperaturas estão mais altas e a umidade média varia entre $70 \%$ e $75 \%$. O uso de ar-condicionado como estratégia ativa para o calor representa $2,81 \%$ das horas anuais.

O desconforto causado pelo frio é quase nulo, chega a ser $0,16 \%$ do total de horas.

A zona de conforto apresentou apenas 25,7 \% das 8760 horas anuais, sendo formados predominantemente por valores de janeiro, maio, junho, julho e dezembro (Tabela 1), isso significa aproximadamente 2251 horas anuais de conforto.
Tabela 1 - Estratégias bioclimáticas para cada mês.

\begin{tabular}{|c|c|}
\hline MÊS & $\begin{array}{c}\text { Estratégias Bioclimáticas para cada mês (\% } \\
\text { do total de horas mensais) }\end{array}$ \\
\hline \multirow[b]{2}{*}{ Janeiro } & »Conforto: 55,15 \\
\hline & „Ventilação: 44,88 \\
\hline \multirow[b]{2}{*}{ Fevereiro } & „Ventilação: 8,64 \\
\hline & $\begin{array}{c}\text { „Ventilação/Alta Inércia/Resfriamento } \\
\text { Evaporativo: } 91.38\end{array}$ \\
\hline Março & »Ventilação: 100.04 \\
\hline \multirow{3}{*}{ Abril } & »Conforto: 4,15 \\
\hline & „Ventilação: 54,28 \\
\hline & $\begin{array}{c}\text { „Ventilação/Alta Inércia/Resfriamento } \\
\text { Evaporativo: } 41,59\end{array}$ \\
\hline \multirow[b]{2}{*}{ Maio } & »Conforto: 38,48 \\
\hline & $\begin{array}{l}\text { »Ventilação/Alta Inércia/Resfriamento } \\
\text { Evaporativo: } 61,57 \\
\end{array}$ \\
\hline \multirow[b]{2}{*}{ Junho } & »Conforto: 72,84 \\
\hline & $\begin{array}{c}\text { »Ventilação/Alta Inércia/Resfriamento } \\
\text { Evaporativo: } 27,17\end{array}$ \\
\hline \multirow[b]{2}{*}{ Julho } & »Conforto: 83,34 \\
\hline & $\begin{array}{c}\text { »Ventilação/Alta Inércia/Resfriamento } \\
\text { Evaporativo: } 16,66\end{array}$ \\
\hline Agosto & $\begin{array}{l}\text { »Ventilação/Alta Inércia/Resfriamento } \\
\text { Evaporativo: } 100,00\end{array}$ \\
\hline \multirow[b]{2}{*}{ Setembro } & »Conforto: 0,07 \\
\hline & $\begin{array}{c}\text { »Ventilação/Alta Inércia/Resfriamento } \\
\text { Evaporativo: } 99,95\end{array}$ \\
\hline \multirow[b]{2}{*}{ Outubro } & »Conforto: 8,07 \\
\hline & $\begin{array}{c}\text { „Ventilação/Alta Inércia/Resfriamento } \\
\text { Evaporativo: } 91,95\end{array}$ \\
\hline \multirow{3}{*}{ Novembro } & „Conforto: 22,84 \\
\hline & „Ventilação: 30,70 \\
\hline & $\begin{array}{l}\text { »Ventilação/Alta Inércia/Resfriamento } \\
\text { Evaporativo: } 46,47\end{array}$ \\
\hline \multirow{2}{*}{ Dezembro } & »Conforto: 49,31 \\
\hline & »Ventilação: 50,72 \\
\hline
\end{tabular}

Fonte: Autores, 2019.

A utilização das estratégias passivas de aquecimento e de resfriamento no projeto proporciona a redução do tempo de utilização de sistemas artificiais para atingir o conforto térmico, consequentemente reduz o consumo de energia nas edificações.

Ao buscar referências de lugares com o clima semelhante ao de Palmas, TO, foi possível encontrar um estudo aplicado por Miranda et al (2010) de Revista Desafios - v. 7, n. 2, 2020 
processamento do arquivo climático de Cuiabá, MT, ambas fazem parte da mesma zona bioclimática 7 pela NBR 15 220- 3: 2005. Ao final, a carta bioclimática gerada pelo programa AnalysisBio para Cuiabá possui resultados análogos ao clima de Palmas.

Desta maneira, para Cuiabá, contabilizando o total de pontos em cada zona, de acordo com o relatório final disponibilizado pelo Analysis Bio, foi possível constatar que $25,8 \%$ do total de horas anuais, estão na zona de conforto térmico, tendo-se 2.260 horas do ano climático típico com temperaturas entre $18^{\circ} \mathrm{C}$ a $29^{\circ} \mathrm{C}$. Algo semelhante as horas de conforto de Palmas com o total de 2251 horas, como já citado.

Já a situação de desconforto térmico para Cuiabá está presente em $74,10 \%$ do total das horas, sendo $68,5 \%$, ou 6000,6 horas, de desconforto devido ao calor, e uma reduzida porcentagem de 5,64\% devido ao frio. Se compararmos as 6509 horas de desconforto pelo calor anuais de Palmas, também é possível notar uma boa compatibilidade entre as simulações do TRY de ambas. O mesmo acontece com o desconforto pelo frio, embora nos dois casos não seja significativo, Palmas aparece com apenas $0,16 \%$

\section{CONCLUSÃO}

A partir da inserção do Ano Climático de Referência no programa AnalysisBIO, as estratégias mais adequadas para o clima local em pelo menos 7 meses do ano, são a junção de ventilação natural, alta inércia, resfriamento evaporativo e ar condicionado para esses períodos de clima local quente e seco. Tais estratégias permitem tanto a correção do desconforto por calor, quanto para regular a umidade nos ambientes internos da edificação. Os meses restantes apresentam somente a ventilação natural para a correção do desconforto por calor. Tais estratégias são indicadas na NBR 15220-Desempenho térmico de edificações - para a Zona Bioclimática 7, no qual faz parte a cidade de Palmas. No mês de junho e julho pode- se observar o período de maior conforto ambiental. Esse resultado provavelmente foi devido ao fato de que esses meses apresentam as temperaturas locais mais baixas do ano. $\mathrm{O}$ mês de dezembro apresentou como sendo o mês mais desconfortável, no entanto, vale a pena questionar a compatibilidade de adequação desse resultado ao clima local, isso porque esse mês do ano de 2015, foi o que mais possuía falhas em seus dados climáticos, seguido do mês de novembro.

\section{AGRADECIMENTO}

Agradecemos ao Programa de Iniciação científica/ CNPQ por contribuir financeiramente.

Todos os autores declararam não haver qualquer potencial conflito de interesses referente a este artigo.

\section{REFERÊNCIAS}

ABNT, ASSOCIAÇÃO BRASILEIRA DE NORMAS TÉCNICAS. NBR 15220-3:2005 - Desenpenho térmico de edificações - Parte 3 - Zoneamento bioclimático brasileiro e diretrizes construtivas para habitações unifamiliares de interesse social.

ASHRAE, (1993). Weather Data and Design Conditions. In: ASHRAE Handbook - Fundamentals, New York, cap. 24, 1993.

BARBOSA, Dejean da C; LIMA, Mariana B. Arquitetura bioclimática: recomendações apropriadas para Palmas/To. Anais Eletrônicos. $1^{\circ}$ Jornada de Iniciação Científica e extensão do IFTO, 2010.

CAMPOS. R. B.; SAKIYAMA. N. R. M.; OLIVEIRA. C. C. (2016) Análise de Dados Climáticos das Estações Convencional e Automática em Teófilo Otoni - MG Estratégias Bioclimáticas para a Construção Civil- Revista Científica Multidisciplinar Núcleo do conhecimento. Ano 1. Vol. 9. pp 914-937, 2016.

CARLO, J; LAMBERTS, R. Processamento de Arquivos Climáticos Para Simulação do Desempenho Energético de Edificações. In: ARQUIVOS Climáticos. Florianópolis: UFSC/LabEEE. 2005.

DIAS, Adriana. Avaliação das condições de conforto térmico e acústico de salas de aula em escola de tempo integral- Estudo de caso da escola Padre Josimo em Palmas (TO). Dissertação- Universidade de Brasília, Faculdade de Arquitetura e Urbanismo, 2009 141p. 2009.

FLORES, M. G. Geração da base climática de Santa Maria, RS para análise de desempenho térmico e Revista Desafios - v. 7, n. 2, 2020 
eficiência energética em edificações. 2014. Dissertação de Mestrado em Engenharia Civil e Ambiental. Universidade Federal de Santa Maria.

GIVONI, Baruch. Confort, climate analisys and building design guidelines. Energy and Building Lausanne, v. 18, p.11-23, jul.1992.

GUIMARÃES, I. B. B. Análises de incertezas e sensibilidade de arquivos climáticos e seus impactos em simulações computacionais termo energéticas. Dissertação de mestrado, Universidade Federal de Viçosa, 2016. Acesso em 07 de fevereiro de 2020. Disponível em: http://bdtd.ibict.br/vufind/.

LAMBERTS, R.; DUTRA, L.; PEREIRA, F., (1997). Eficiência Energética na Arquitetura. São Paulo: PW Editores.

LANHAM, Ana; GAMA, Pedro; Renato BRAZ, Renato. Arquitetura Bioclimática Perspectivas de inovação e futuro. Seminários de Inovação, Instituto superior Técnico de Lisboa. Universidade Técnica de Lisboa, 2004.

LEÃO, E. F. T. B. (2007). Carta bioclimática de CuiabáMato Grosso, Dissertação (Mestrado em Física e Meio Ambiente) - Curso de Pós-Graduação em Física e Meio Ambiente da Universidade Federal de Mato Grosso, Cuiabá, MT, 147p.
LIMA, M. B. de. Et alii. Proposta de habitação bioclimática para o clima quente e seco. VIII Encontro Nacional e IV Encontro Latino-Americano sobre Conforto no Ambiente Construído. Maceió, 2005.

MIRANDA, S. A. OMAR, L. G. APOLONIO, R. CARVALHO, B. C. Processamento de arquivo climático para avaliações de conforto ambiental em cuiabá - MT. Encontro Nacional de Tecnologia do Ambiente Construído. XII ENTAC, 2010

OLGYAY, V. Design with Climate. Bioclimatic Approach to Architectural Regionalism. 1963. 4th ed. Princeton, New Jersey. U. S. A.: Princeton University Press.

RORIZ, M. Arquivos Climáticos de Municípios Brasileiros. Florianópolis: UFSC/Laboratório de Eficiência Energética em Edificações- LabEEE, 2012a.

ROSSI, F. A. KRUGER, E. Atualização do Ano Climático de Referência de Curitiba, 2015. Disponível_em:_https://www.researchgate.net/publication/ 268354042. Acesso em 30 de março de 2018. 